\title{
Chapter 13 \\ Knowledge for Transformational \\ Adaptation Planning: Comparing \\ the Potential of Forecasting \\ and Backcasting Methods for \\ Assessing People's Vulnerability
}

\author{
Giuseppe Faldi and Silvia Macchi
}

\begin{abstract}
In recent years there has been growing recognition that people's vulnerability is not just as an outcome of possible climate impacts, but rather a dynamic contextual characteristic of a socio-ecological system. Accordingly, along with the acknowledgement of the close connection between climate change adaptation and sustainable development, the scientific debate on adaptation has increasingly focused on the issue of transformation of current systems in response to a changing environment. The need for transformational adaptation, especially in high vulnerability contexts, induces planners to broaden and diversify both knowledge and methods to deal with the growing uncertainty and complexity of socio-ecological systems. By focusing on future studies, this chapter aims to explore the transformational knowledge contribution of forecasting and participatory backcasting methods in assessing people's vulnerability using the case study of coastal Dar es Salaam (Tanzania). Participatory backcasting helps understanding contextual vulnerability and community aspirations, and defining shared adaptation goals and action. Conversely, forecasting proves to be fundamental for the identification of boundary conditions and system thresholds relevant to a specific problem, thus providing knowledge that is valuable for integrating global and local perspectives.
\end{abstract}

Keywords Transformational adaptation - Vulnerability • Backcasting • Forecasting • Dar es salaam

G. Faldi $(\bowtie) \cdot$ S. Macchi

DICEA-Department of Civil Constructional and Environmental Engineering,

Sapienza University of Rome, Via Eudossiana 18, 00184 Rome, Italy

e-mail: giuseppe.faldi@yahoo.com 


\subsection{Toward Transformational Adaptation: The Need to Innovate Vulnerability Assessment Methods}

In recent years, there has been a recognition of the close connection between Climate Change (CC) adaptation and sustainable development, as well as the consolidation of an interpretation of vulnerability as not only the result of possible impacts of CC but also as a contextual characteristic of a Socio-Ecological System (SES) (contextual vulnerability) (O'Brien et al. 2007). The debate on adaptation has become increasingly focused on the transformation of current systems in response to $\mathrm{CC}$, and the multitude of economic, political, environmental, and social changes that many communities, cities and regions must address.

Making reference mainly to Resilience and Transition theories (Martens and Rotmans 2005; Folke 2006; Olsson et al. 2006; Van der Brugge and Rotmans 2007), the literature on CC adaptation understands transformation as a structural modification of an SES deriving from a series of specific interacting changes that occur in different domains (economic, cultural, technological, ecological, and institutional), and which may occur as a response to a specific spontaneous or deliberate event or action, or develop gradually over time (IPCC 2014).

According to this perspective, adaptation is no longer understood as simply securing a city with respect to a possible climate impact (incremental adaptation), but also as an opportunity to favour the deployment of transformative actions oriented towards sustainability and equity goals (transformational adaptation and change) (O'Brien 2012; Park et al. 2012; IPCC 2014). More specifically, incremental adaptation is considered the reproduction of actions and behaviours that have already been tested in the past, or that are currently underway, and aimed at maintaining the integrity and essence of a system with respect to the impacts of CC (Park et al. 2012). Vice versa, transformational adaptation includes the actions and behaviours that modify the fundamental attributes of a system in response to a determined impact of $\mathrm{CC}$, and transformational change is understood as a modality of reducing risk and the vulnerability, not only by adapting to $\mathrm{CC}$, but also by challenging those social and economic structures that have contributed to $\mathrm{CC}$, and to social vulnerability more generally (IPCC 2014).

In particular, the need for transformational adaptation and change has been emphasized (contemporaneously with incremental action) especially in contexts like Sub-Saharan urban environments characterized by high degrees of social vulnerability and exposure to severe climatic stress (Kates et al. 2012).

This emerging theoretical perspective on adaptation led the scientific community to identify a broad knowledge gap as regards how to plan in practice in a way that favours transformational adaptation and change in an SES, specifically for contexts of high social vulnerability (IPCC 2014).

In order to contribute to filling this gap, we first assume that promoting the conditions to facilitate a system transformation begins with changing the way we represent and understand a given question upon which to intervene ("transformation of understandings" for "transformation of practices") (Dente 2014). The type of 
knowledge upon which the decision-making process is based as well as the way in which that knowledge is constructed, therefore, become fundamental elements in favouring a transformative process.

The transformational perspective on adaptation therefore induces planners to broaden and diversify both knowledge and methods to deal with the growing uncertainty and complexity of socio-economic, environmental, and climatic systems. In particular, planners need to update the most widely-used climate proofing methods for vulnerability assessment (such as impact/risk analyses, developed predominantly for the management of natural disasters), as they are unable to fully grasp the future uncertainty and the multidimensional vulnerability processes occurring in an SES, and, therefore, favour an incremental vision of adaptation. Planners also need to research alternative or complementary methods for supporting decision-making that focus the assessment process directly on the most vulnerable actors and their experiential knowledge, and that are able to embrace the uncertainty and complexity of the multi-stress context in which vulnerability dynamics are produced, and to propose long-term future projects that consider people's legitimate expectations of change (Eakin and Luers 2006; Pelling 2011; O’Brien 2012; IPCC 2014).

In pursuit of that goal, the present work focuses on the broad field of future studies in which scenario methods are increasingly used in planning for adaptation to CC (Börjeson et al. 2006), and seeks to explore the knowledge contribution towards transformational adaptation on a local scale that arises from the use of the two main scenario building approaches for assessing people's vulnerability: forecasting and backcasting.

The argument is explored through the case study of Dar es Salaam (Tanzania), where a vulnerability assessment to access to water of the coastal peri-urban population was developed combining forecasting and participatory backcasting in the framework of the Project "Adapting to Climate Change in Coastal Dar es Salaam" (ACC Dar) (www.planning4adaptation.eu).

After illustrating the use of the two scenario building approaches in the vulnerability assessment process, the chapter presents the case study, the scenario methodology, the research method, the results and emerging knowledge contribution, ending with the potential use of forecasting and participatory backcasting methods for transformational adaptation planning.

\subsection{Scenario Analysis for Vulnerability Assessment}

The growing interest in adaptation has been translated into progressively more complex methodologies to support the definition of adaptation strategies: from the "classic" environmental impact studies to the more detailed "first" and "second generation" climate change vulnerability studies that encompass social parameters in the assessment process (Füssel and Klein 2006). Among the various methodological instruments applied to adaptation planning and vulnerability assessment in particular, scenario analysis methods are increasingly used because they are 


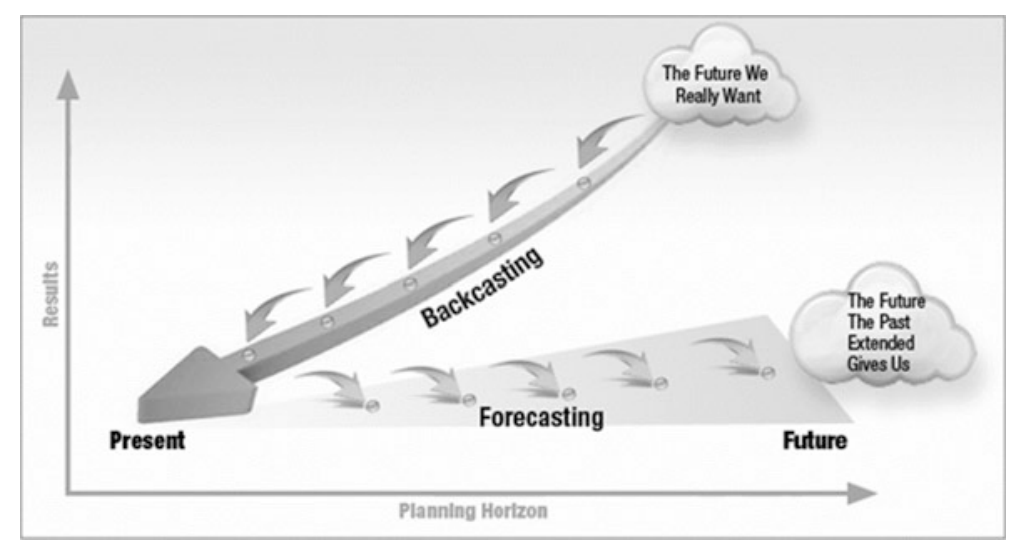

Fig. 13.1 Different perspectives of the forecasting and backcasting approaches (mod. from Roche 2012)

considered useful in addressing situations of high uncertainty characterized by low levels of control (Peterson et al. 2003; Börjeson et al. 2006).

Within the field of future studies, two main schools of thought on scenario analysis can be distinguished that correspond to two different approaches and perspectives on scenario building (Fig. 13.1) (Dreborg 1996; Van Notten et al. 2003).

The first is the forecasting approach (exploratory scenario: what could possibly happen?), developed within the broad school of strategic planning. In the strategic vision, scenario analysis represents a method that, through the construction and exploration of possible stories and paths that move from the present to the future, can be used as a learning process aimed at understanding the relations between different drivers and variables in a system, thus facilitating the development of a certain degree of flexibility in the system in question as regards potential future events (Van der Heijden 2005; Lindgren and Bandhold 2009).

The second is the backcasting approach (normative scenario: what would be preferable to have happen?), which is framed in the broader field of sustainability planning (Robinson 1990; Dreborg 1996), where is it used in a variety of spheres, such as studies on the "transition to sustainability" for socio-technological (Rotmans et al. 2001) and urban (Hopkins 2008) transition. According to that approach, scenario analysis is used primarily to define one or more desirable visions and images of the future that present a solution to a given problem, and secondarily, moving the perspective from the future to the present for the definition of the actions and changes necessary in order for such future images to emerge (Vergragt and Quist 2011). A recent evolution of this approach is so-called participatory backcasting, which is based on the involvement of different actors (experts and non-experts) in the creation of a future vision and the development of future-present paths with the goal of promoting a social learning process for the actors involved (Robinson 2003; Quist and Vergragt 2006; Quist 2007). 
As regards the use of scenario analysis in CC adaptation studies, the scenario methods that draw from the forecasting approach, albeit with substantial differences in their scenario building techniques (top-down vs. bottom-up, quantitative vs. qualitative, analytic vs. participatory), have played and continue to play a dominant role in impact studies and CC vulnerability studies and are thus the most widely used in adaptation planning, especially at the regional and supra-regional levels (e.g. SRES scenarios, socio-economic scenarios, down-scaled climatic scenarios) (IPCC 2000; Swart et al. 2004). In particular, forecasting scenario analysis is especially used in CC studies to explore specific environmental and socio-economic questions or phenomena that have a direct correlation to $\mathrm{CC}$, and to understand, visualise, and analyse the relative main future trends, impacts, and climate risks, in order to identify the vulnerability of the people exposed and to thus facilitate the identification and prioritization of various adaptation policy responses (IPCC 2014).

In any case, despite their wide use in adaptation planning, various authors (Gydley et al. 2009, O'Brien 2012) have emphasized how the use of the "more consolidated" forecasting methods in the vulnerability assessment process cannot help but support an incremental view of adaptation, especially on a local scale, because forecasting, which is based on the exploration of dominant trends and is incapable of taking contextual vulnerability dynamics and their future uncertainty into account, tends to consider the future as a restatement of the mechanisms of the present, thus favouring a conservative perspective on adaptation.

Contrariwise, backcasting is suggested in the literature (Giddens 2009; Van der Voorn et al. 2012; IPCC 2012) as theoretically able to favour the unfolding of transformative processes in that, by moving from a utopian and desirable future, it tends to detach from present dynamics and, especially if applied in a participatory way, can introduce certain elements into the adaptation planning process that can promote transformation (shared vision and social learning). In any case, despite the hypothetical recognition of this potential, its use at the practical level for informing local adaptation planning has not yet been widely experimented.

\subsection{Levels of Knowledge for Planning Adaptation Locally: Understanding the Access to Water in Coastal Dar es Salaam}

\subsubsection{Study Area and Methods}

The case study was carried out in Dar es Salaam (Fig. 13.2), the largest city in Tanzania, and one of the most important metropolises of eastern Sub-Saharan Africa. In the first phase of the developed vulnerability assessment process (Fig. 13.3a), a forecasting method was applied analytically to study a biophysical phenomenon at the urban level that could be influenced by CC, namely seawater intrusion into the coastal aquifer. 


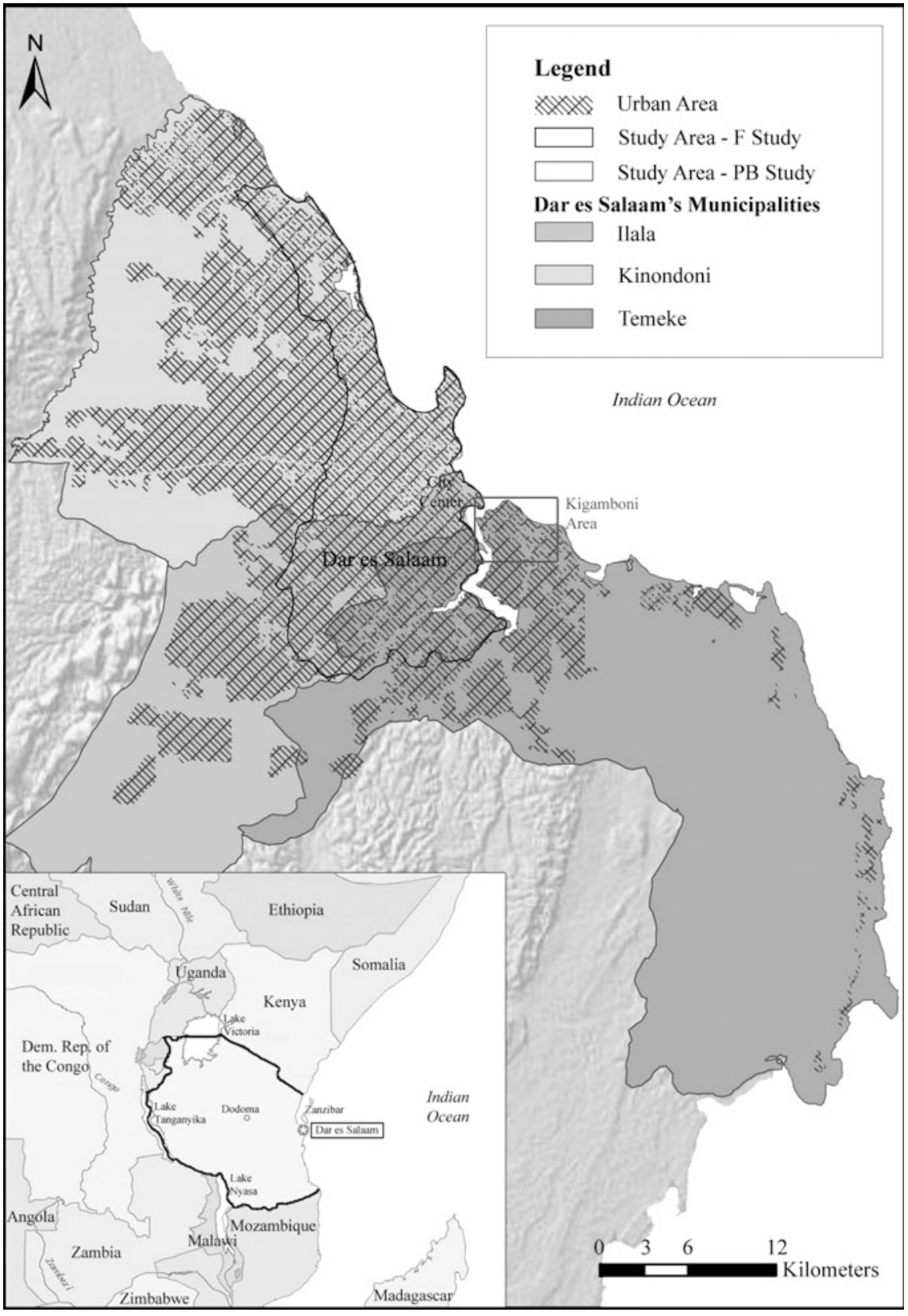

Fig. 13.2 Dar es Salaam Region and the areas of the Forecasting (F) and Participatory Backcasting (PB) studies 


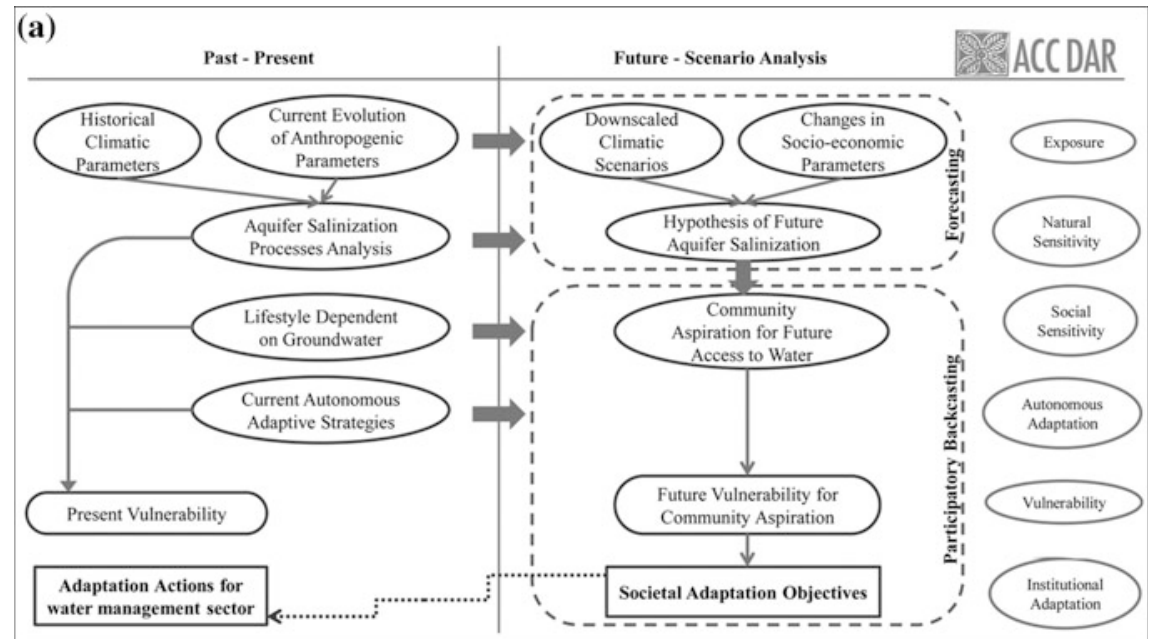

(b)

\section{Current State}

Exposure

Climatic and anthropogenic influences on hydrogeological dynamics

Natural Sensitivity

Current seawater intrusion assessment
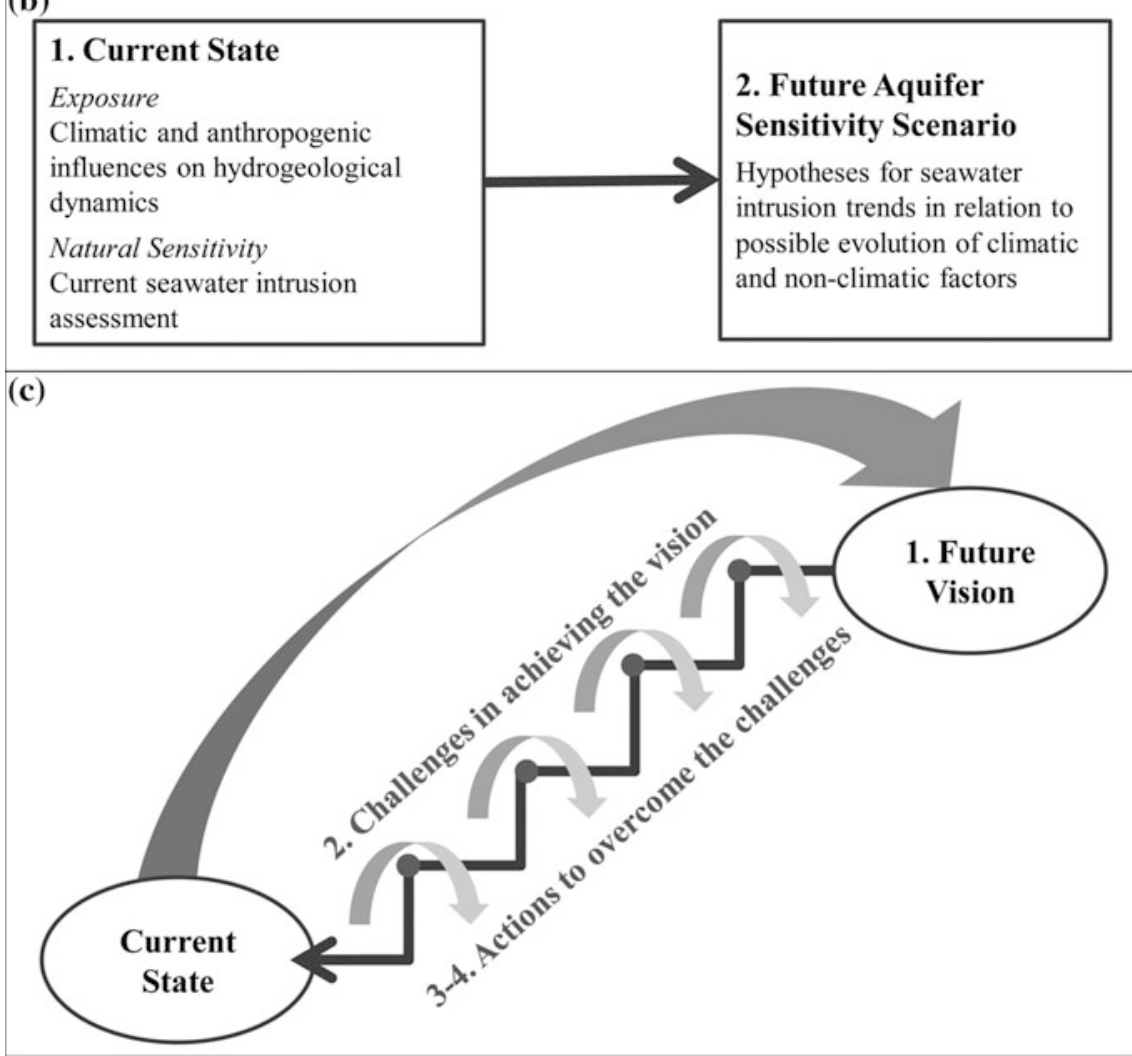

Fig. 13.3 The different phases of the developed vulnerability assessment process (a), and the conceptual frameworks of the forecasting (b) and participatory backcasting (c) methodologies 
In the second phase, the use of a participatory backcasting method was tested to study access to water in a specific peri-urban coastal community in Dar es Salaam. In general, access to water currently represents an emerging problem for the city's coastal communities due to the increasing salinization of the aquifer, caused by anthropogenic pollution (Mato 2002; Mjemah 2007) and by growing seawater intrusion (Mtoni et al. 2012; Faldi and Rossi 2014). In fact, as a result of the inefficiency of the municipal water system in meeting the increasing water demands of a growing population - it currently serves $25-30 \%$ of the total water demand of the population (UN-Habitat 2009), which is estimated as 4.36 million inhabitants with a growth annual rate of 5.6\% (URT 2012)-groundwater has become increasingly important for supporting human activities, especially in unplanned peri-urban areas (URT 2011).

Moreover, the recent changes in climatic characteristics in Dar es Salaam can contribute to the impoverishment of local freshwater resources and additional demand for groundwater, particularly the significant decreasing trend in average rainfall (from approximately $1200 \mathrm{~mm} / \mathrm{year}$ in 1960 to approximately $1000 \mathrm{~mm} /$ year in 2010), and the increasing trend in average mean temperature (Rugai and Kassenga 2014).

The purpose of the forecasting study was to analyse the temporal evolution of seawater intrusion into the coastal aquifer in Dar es Salaam and the climatic and anthropogenic influences on the hydrogeological dynamics of the environmental system, and to develop qualitative scenarios of future seawater intrusion trends with respect to the possible evolution of the climatic and non-climatic factors considered (i.e. aquifer sensitivity to seawater intrusion). The methodology for assessing the aquifer's sensitivity to seawater intrusion (Sappa et al. 2013) (Fig. 13.3b), applied to a specific study area, consisted of two analytical steps (Table 13.1).

The backcasting study was developed through the use of the Theatre of the Oppressed (TO) (Boal 1992) as a participatory tool, and sought to explore the hopes of the community as regards access to water, the challenges that could prevent them from realizing those hopes, and the collective development of possible strategies for overcoming obstacles and fulfilling their needs. The core idea of the developed backcasting methodology (Faldi et al. 2014) (Fig. 13.3c) was to begin the process

Table 13.1 Analytical steps of the forecasting methodology

\begin{tabular}{l|l}
\hline Steps of the F methodology & Analysis methods \\
\hline $\begin{array}{l}\text { 1. Understanding current aquifer } \\
\text { exposure and sensitivity }\end{array}$ & $\begin{array}{l}\text { Seawater intrusion assessment through hydro } \\
\text { chemical methods, namely physical and chemical } \\
\text { testing of a monitored network of representative } \\
\text { boreholes from } 2001 \text { to } 2012 \\
\text { - Analysis of climatic and anthropogenic influences } \\
\text { on hydrogeological dynamics through investigation } \\
\text { of the temporal evolution of the piezometric surface } \\
\text { and Active Groundwater Recharge (AGR) }\end{array}$ \\
\hline $\begin{array}{l}\text { 2. Exploring future aquifer sensitivity } \\
\text { scenario to seawater intrusion }\end{array}$ & $\begin{array}{l}\text { Development of qualitative hypotheses for seawater } \\
\text { intrusion trends related to the possible future } \\
\text { evolution of climatic and non-climatic factors }\end{array}$ \\
\hline
\end{tabular}


Table 13.2 Steps of the participatory backcasting methodology

\begin{tabular}{l|l}
\hline Backcasting phases & Steps of the PB-TO methodology \\
\hline Community workshop & $\begin{array}{l}\text { 1. Development of a shared vision of future access to water } \\
\text { 2. Identification of the challenges in achieving that vision }\end{array}$ \\
\hline $\begin{array}{l}\text { Various public Forum } \\
\text { Theatre sessions }\end{array}$ & $\begin{array}{l}\text { 3. Preparation of a theatrical representation staging the vision } \\
\text { and related challenges that emerged during the workshop } \\
\text { 4. Collective exploration of alternative actions and strategies to } \\
\text { overcome challenges }\end{array}$ \\
\hline
\end{tabular}

by defining the community's shared future vision regarding access to water, to then look backwards from that future to the present situation in order to identify the challenges that might arise as they work towards achieving that vision, and finally to identify strategies and actions for overcoming those challenges and achieving the desired future. The methodology is organized in 4 consecutive steps, carried out during a two-phase exercise (Table 13.2). By using a variety of creative TO techniques, active community participation is fostered throughout the entire process. In fact, participants' interaction represents the core of the process, which relies heavily on a qualitative traditional knowledge system, made up of words, images, stories, and scenes. The developed methodology was tested though a backcasting exercise carried out in Kigamboni ward, a peri-urban coastal area located in the south of Dar es Salaam. The first phase of the exercise involved 24 young people, while in the second phase 11 public Forum Theatre events were performed in various areas within the Kigamboni ward, involving in total more than 2000 people.

The results that emerged from the forecasting and backcasting studies were evaluated with respect to the knowledge contribution provided, identified in terms of:

- understanding the problem of the access to water induced by the use of a given method (way of addressing the future uncertainty and complexity of the context)

- objectives resulting from that understanding (consideration on people's expectations of change)

- action resulting from that understanding.

\subsection{Results of the Forecasting and Participatory Backcasting Studies}

In the first phase of the vulnerability assessment, the fundamental knowledge contribution of the use of forecasting applied to the study of environmental systems consisted mainly in its ability to provide a better understanding of pressure factors determining the seawater intrusion. This allowed for identification of the boundary conditions of the disruption and the thresholds of the SES in relation to the evolution of the disruption and, consequently, the determination of general principles identifying the supra-local limits of local adaptation initiatives. In particular, the forecasting study shows an increase in the areas affected by seawater intrusion in the period 2001-2012, and how this increase is correlated to the dropping 
piezometric level, the over-exploitation of the aquifer, and the decrease in average AGR (20\%) due to the combined effects of CC (rainfall decrease and mean temperature rise) and anthropogenic causes (increasing soil sealing due to an increase in urban areas from 40 to $65 \%$, and a decrease in soil and vegetation areas from 55 to $32 \%$ ). The analysis of water demand over the 10 -year period also provided an estimate of the exploitation of groundwater by the population.

The combined decrease in resource availability and increase in the estimated groundwater withdrawal suggest that unplanned and uncontrolled groundwater exploitation is a significant factor of hydrogeological imbalance, one that can be related to a general increase of the aquifer's sensitivity to seawater intrusion (Sappa et al. 2013). The qualitative hypotheses regarding the future development of climatic and anthropogenic variables, considering the persistence of current trends, indicate a drastic decline in annual AGR in the future.

At the same time, the rate of groundwater extraction is expected to grow, due to increasing population. The comparison of the AGR and water demand values, estimated according to different water demand scenarios, indicate that the water demand is already equal to the AGR value, with possible negative consequences for the population (Fig. 13.4).

(a)

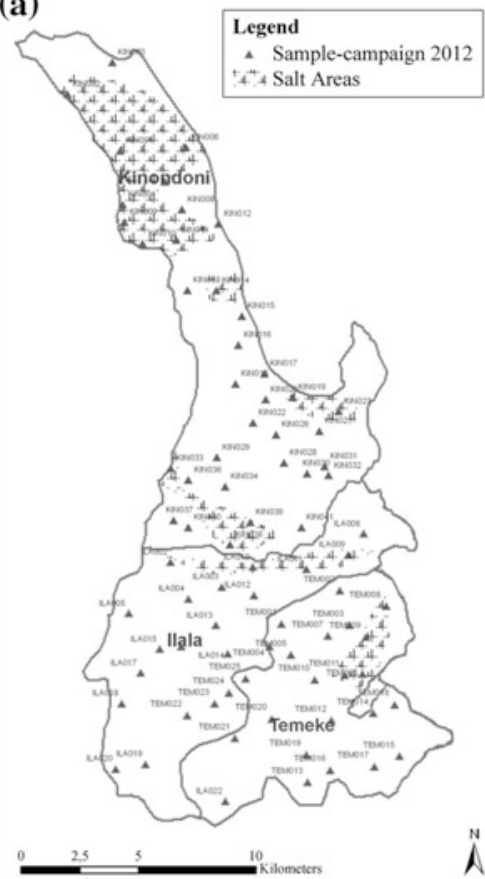

(b)

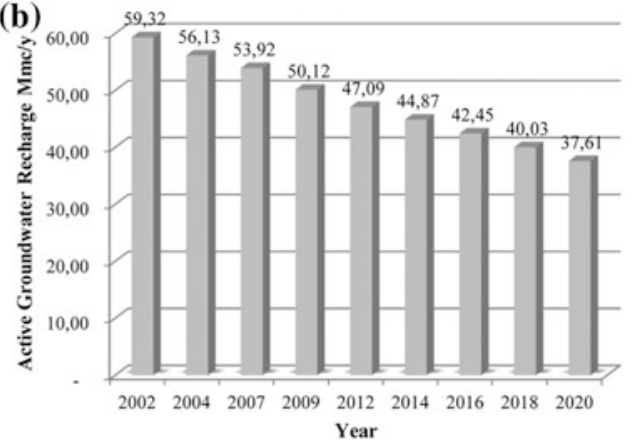

(c)

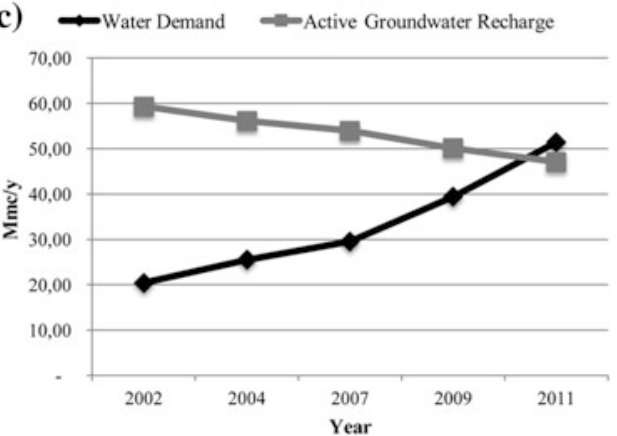

Fig. 13.4 Some specific results of the forecasting study (mod. from Sappa et al. 2013): a Sectors affected by seawater intrusion (2012), b Estimation of future evolution of AGR, c AGR versus water demand (2001-2012) 
The forecasting study has therefore demonstrated that the problem has already reached a limit state, providing in addition an order of relevance for the drivers of this disruption. In this specific case, $\mathrm{CC}$ represents a possible multiplier of the effects of the disruption, but cannot be considered a primary stress factor in light of the weight of over-exploitation of the aquifer and soil sealing in recent years.

Thus, with respect to the identification of boundary conditions and system thresholds, the forecasting study has proven able to identify those determinative factors that are currently exceeded, or whose future development according to current trends would entail scenarios and tendencies to be avoided (business as usual scenario). This knowledge is fundamental to a vulnerability assessment aimed at adaptation in transformational way, in that it offers the possibility of identifying whether and where a change in the SES is necessary with respect to a specific disruption. Through the use of forecasting in studying specific disruptions to the environmental system, it is therefore possible to define adaptation objectives beyond the local level, which adaptation initiatives should always follow in order to limit an already excessive disturbance or to recognize one that has reached critical levels.

In the case study, the conservation and sustainable use of groundwater resources is therefore framed as a priority general principle with fundamental significance for the coastal communities of Dar es Salaam.

Despite the emergence of such strata, forecasting study was unable to understand the contextual dynamics affected by the disturbance and the eventual existence of cross-scalar influences, namely the internal factors and variables of the context that could constitute additional drivers of the disturbance. This contributes to an increase in uncertainty when predicting what the future dynamics of an SES could be with regard to the evolution of the disturbance.

In the second part of the assessment process, analysis of the results of the practical experimentation of participatory backcasting allowed for the definition of a framework of knowledge elements that participatory backcasting, when applied at the community level, can bring to a vulnerability assessment aimed at transformational adaptation.

A first knowledge element that emerged from the use of participatory backcasting in the vulnerability assessment is strictly linked to the visioning process. The construction of a shared future vision highlighted in a clear and detailed way the desires and hopes of the community as regards access to water: from the legitimate expectation of stable access to good quality water at a reasonable price, which would be guaranteed by having access to multiple water sources, to the desire to generate one or more socio-economic activities at both the individual and community level. In particular, within the desired vision (Fig. 13.5a) every family in the community has access to a sufficient amount of water for their domestic and productive purposes (2000 L/day per household). Water supply should also be ensured by one or more well-constructed, deep wells and various public standpipes connected to the municipal water system. The desire for alternative water sources derives from need to guarantee a continuous and stable supply, so as to relieve people from the need to spend a considerable part of their day obtaining water. In addition, adequate access to water would allow people to develop various 
socio-economic activities on a broader scale, both at the household level (such as family agriculture) and the community level (such as larger-scale agriculture, livestock grazing, ice production for consumption, and fish farming in artificial ponds). Understanding community aspirations therefore provides several kinds of information that is valid at the community level, and the consideration of which in the vulnerability assessment process could facilitate identification of possible specific adaptation objectives that are socially shared and more detailed, and vice versa, not extrapolated from an external vulnerability assessment that is neutral with respect to the context.

Secondly, the use of participatory backcasting for vulnerability assessment allowed for recognition of the multidimensionality of the problem being studied, i.e. by identifying the various vulnerability mechanisms existing in the context and the connections that arise between them. In particular, during practical experimentation it became clear that the question of access to water is very complex and involves a series of interrelated dynamics and multiple transversal aspects of community life. The question is correlated to a series of technical/environmental problems (qualitative degradation of the resource, management and maintenance of water systems to be installed in the area), however limited access to quality water resources also depends on other problematic and interrelated social, economic, and political conditions. In fact, the definition of challenges in achieving the vision facilitated the immediate emergence of a multitude of critical situations linked to access to water: from establishing a common objective within the community as regards the development of possible shared projects to improve their access to water, to obtaining and eventually managing the funds needed to develop such community projects, to the risk that political authorities or individuals representing the community might use their power to obtain personal economic benefits from the failure of community projects (Fig. 13.5a).

This capacity of backcasting allowed for a reduction in the level of uncertainty in understanding the possible evolution of an SES in response to a given environmental or socio-economic pressure factor that directly affects the context, or to a specific already planned (or to be planned) adaptation action. In addition backcasting demonstrates the main causal processes and the level of entry points upon which it is important to focus in order to reduce/transform vulnerability conditions.

Lastly, in the collective exploration of possible actions for overcoming the challenges and achieving the shared vision, the knowledge contribution provided by participatory backcasting demonstrates a more operational character. The public events carried out produced various practices directly proposed by the community. This included actions involving political authorities, proposed in a critical but collaborative way, such as the creation of independent community groups for gathering funds (from various sources) or for gathering, sharing, and distributing information (plans, regulations, laws), as well as the creation of a community water association with a clearly defined political strategy and an economic and technical plan, and finally actions that assumed in some cases the occurrence of illegal acts (breaking of pipes to directly access water or forcing political leaders to step down) (Fig. 13.5b). 
(a) Political Challenge

Critical political situations in the development of community projects Obstacles:

- Difficulty in communication between the community and political leaders

- Public funds allocation without consideration for community needs

- Corruption among politicians and technicians

\section{Social Challenge}

Difficulty in reaching an agreement within the community on a shared project

Obstacles:

- Individual interests prevail over community ones

- Community disorganization and disinformation

- Community disillusioned by the problem solution

- Growing disinterest in public participation
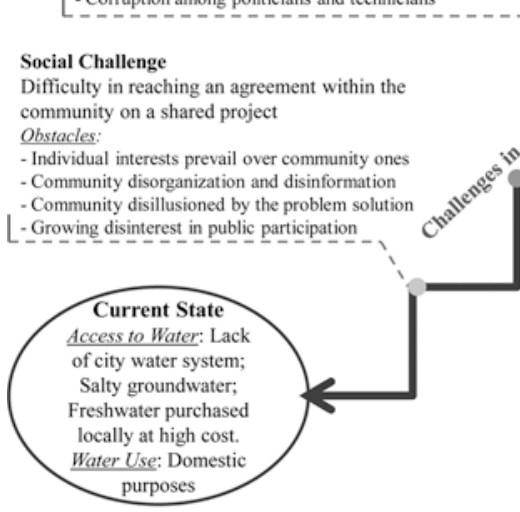

(b)

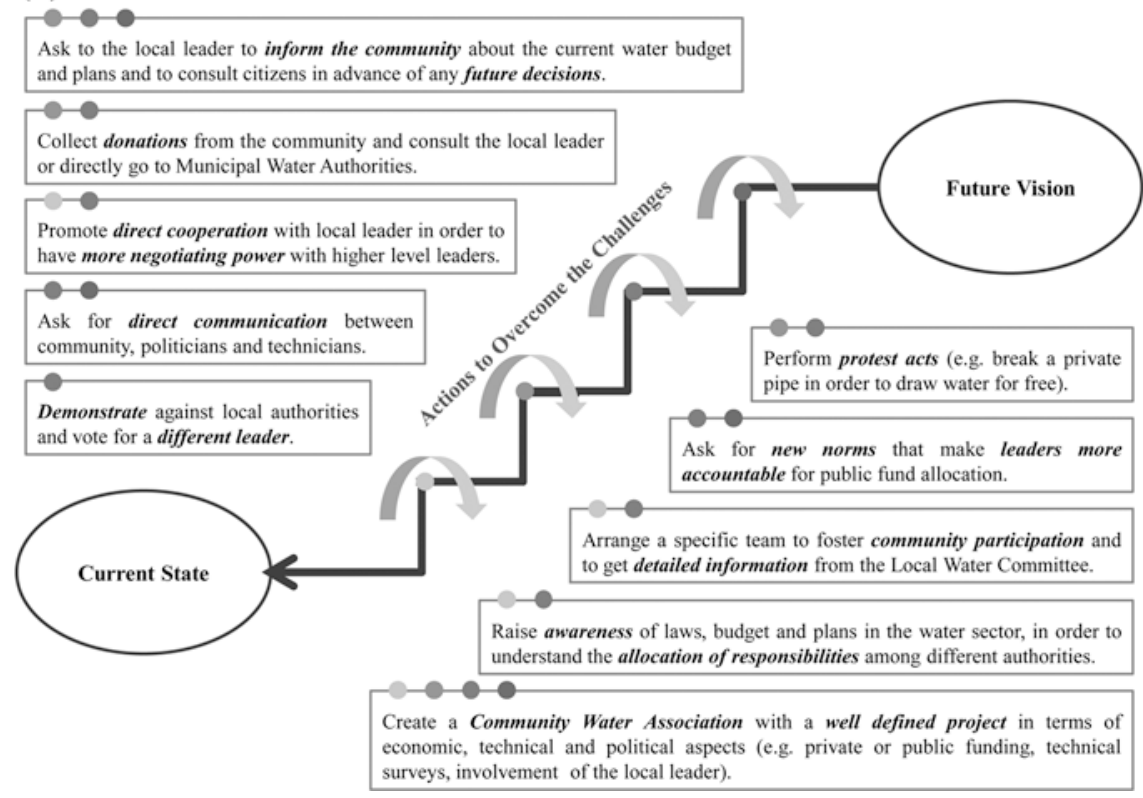

Fig. 13.5 Results of the participatory backcasting (Faldi et al. 2014): Vision and challenges/obstacles in achieving the vision (a), main actions identified during Forum Theatre (b)

The main knowledge contribution that emerges in this phase of the process consists in the capacity of participatory backcasting to demonstrate modalities for carrying out an action, which identify the factors (to consider) and the agents of development (to mobilize) that the community considers potentially able to favour 
change. In particular, the community's cooperation and desire to take on a central and more "informed" role were the main factors in most of the proposed actions, while specific community information groups and local authorities were identified as possible agents of development, should they be involved in community projects.

In any case, the results analysis demonstrates how the use of the participatory backcasting method revealed two principle limits.

The first is correlated to its inability to understand how the pressure factors generated at a supra-local scale can influence contextual vulnerability dynamics. The second limit is the prevalent propensity towards the promotion of solutions and visions that the community has already directly or indirectly experienced, and which often tend to be mostly conservative.

This was the case with the identification of a community well as the main method of water supply that participants desired (although not the only one). That choice, which was widespread in the context, certainly cannot represent a transformative solution as regards the conservation of groundwater resources. The lack of technical knowledge in the visioning process and in the collective exploration of actions therefore proved in this case to be a factor that reduced the community's capacity to define comprehensive courses of action that addressed all the challenges that had been identified.

\subsection{Conclusions}

This chapter contributes to local-scale transformational adaptation using forecasting and participatory backcasting for assessing vulnerability to access to water of a coastal community of Dar es Salaam.

Forecasting and participatory backcasting emerge as potentially complementary rather than alternative methods of supporting planning for transformational adaptation. Participatory backcasting has proven able to overcome the limits of forecasting methods in assessing vulnerability. In fact, forecasting fails to consider the causal processes and contextual dynamics that can cause (or aggravate) people's vulnerability, and favours a conservative perspective when defining adaptation objectives and actions.

As asserted in the literature, if vulnerability is framed exclusively as a static condition that quantifies the level of sensitivity and exposure of a given "exposed unit" to the possible impacts of a biophysical disturbance, it will lead mainly to the identification of incremental adaptation measures. This is evident within the case study: the understanding of the potential evolution and relevance of the seawater intrusion problem leads to the definition of primarily technical-infrastructural or regulatory actions aimed at managing or reducing the disturbance itself. Although the conservation of water resources emerged as a general principle in the urban context of Dar es Salaam, that type of action cannot always be considered effective 
or "no regret" in that the proposed representation is inevitably missing a part of the problem, namely the understanding of how such initiatives can address contextual mechanisms of vulnerability.

The use of participatory backcasting in the vulnerability assessment can therefore fill such gaps, because the alternative representation of the problem that it proposes allows the adaptation process to focus on the dynamics of contextual vulnerability. Participatory backcasting in this case study shows that groundwater salinization represents only a part of the problem. People's vulnerability is characterized as a dynamic condition that results from different and interconnected socio-economic, environmental, and political processes that reveal the reasons why people are unable to access quality water at a reasonable price.

In addition, participatory backcasting has proven potentially able to fill the gaps in forecasting in terms of defining the objectives and actions that come up against the future uncertainty of contextual vulnerability. The identification of shared community objectives, entry points and possible modalities of action provides greater operability in the definition of medium-term adaptation options. This in turn allows for a reduction of uncertainty with respect to the efficacy of such options in the specific context, and optimization of available financial resources, which can be scarce in general, and especially in Sub-Saharan contexts.

According to the representation of the problem proposed in the participatory backcasting, new infrastructure are desired and preferred in the Kigamboni community, but to be an effective and optimal option it would have to be preceded by actions that address various social, economic, and political problems.

From this point of view, participatory backcasting proposes a change in the representation of the problem, which can thus create the conditions for defining local adaptation strategies that are transformative, i.e. oriented not only to the definition of actions for counteracting the effects of $\mathrm{CC}$, but also towards the development of future projects for sustainability and equity.

In any case, the complementarity of the two methods is also clear in the opposite direction. Indeed, the fundamental knowledge contribution that emerged from the forecasting study can potentially compensate the limited technical knowledge within participatory backcasting. In fact, the ability of forecasting to identify, on a supra-local level, the boundary conditions and upper limits beyond which a system change becomes necessary allows for the definition of general objectives that a local adaptation action should seek to meet. Such objectives therefore constitute exclusionary principles for the eventual range of actions defined at the local level.

From the perspective of transformational adaptation, forecasting can therefore bring to the vulnerability assessment process the type of technical knowledge that is necessary to integrate the global into the local perspective. Such knowledge, if introduced into the participatory process, can also allow for an expansion of the horizon of visions and possible courses of action that are available to the community. In the present case study, this translated into the possibility of allowing people to recognize that a community well may not be the most desirable option, thus motivating them to search for alternative solutions that could be equally desirable. 


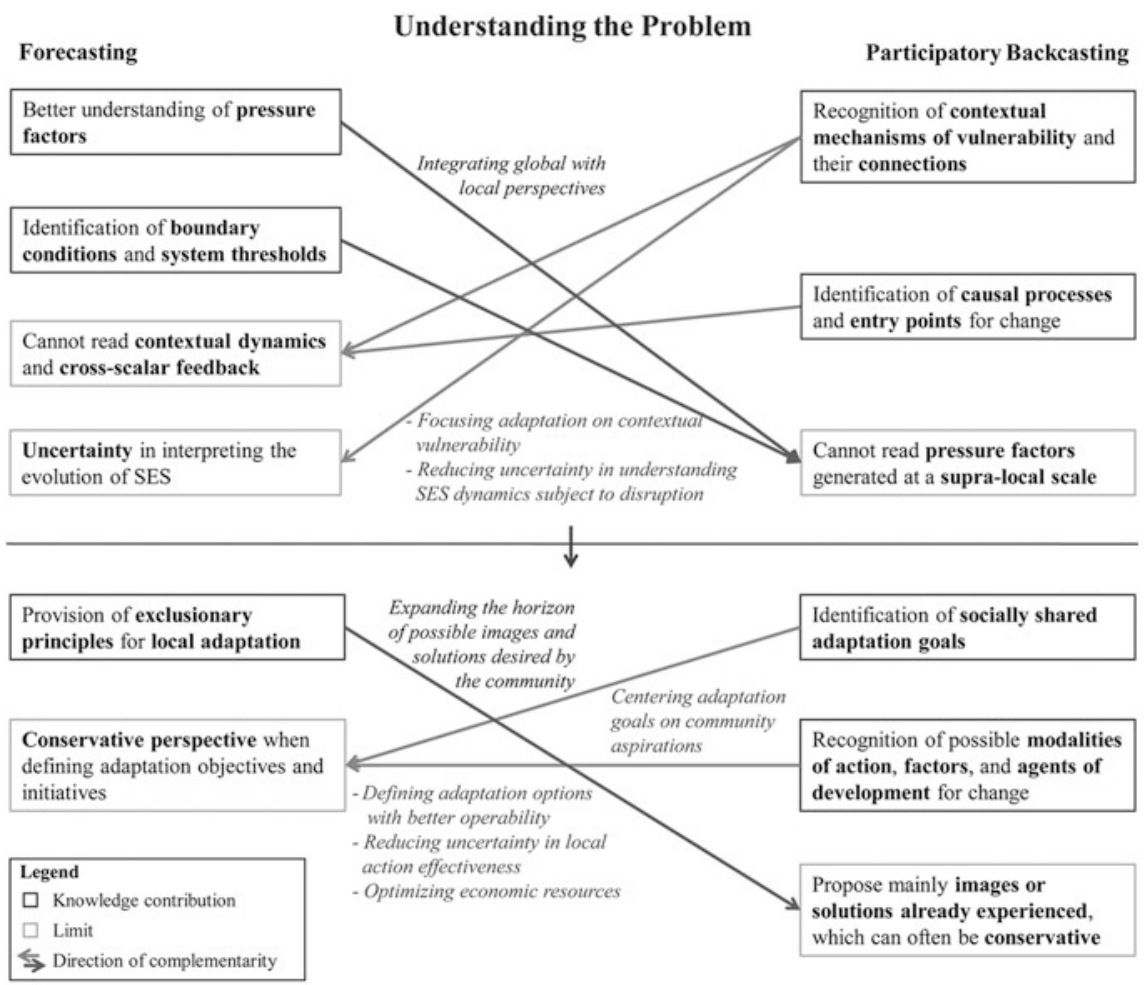

Objectives and Actions resulting from an Understanding of the Problem

Fig. 13.6 Knowledge contribution and limits of forecasting and participatory backcasting: framework of complementarity for transformational local adaptation planning

The framework of the elements of complementarity in the use of forecasting and participatory backcasting in planning transformational adaptation is outlined in Fig. 13.6. On the basis of the experiment results, the configuration of a platform of action for transformational local adaptation in a high vulnerability context involves a change in the representation of contextual vulnerability, and the promotion of a co-production of knowledge. In fact, local traditional knowledge, as mobilized in the backcasting exercise, proved determinative in understanding how vulnerability was formed and "experienced" in the context, and how people wanted to transform it, while technical knowledge, if introduced and "reworked" within the participatory process, is important in defining and potentially expanding the conditions surrounding desires and consequent actions.

In any case, the combination at the community level of the two forms of knowledge and, in this specific case, the two different methods experimented, would require the definition of specific instruments and techniques that introduce technical knowledge into the participatory process, while preventing dynamics of subjugation within the community. How to configure that transdisciplinary dialogue 
of methods at the community level in a way that optimizes potential and limits shortcomings for transformational local adaptation therefore requires further experimentation and study.

\section{References}

Boal, A. 1992. Games for actors and non-actors. Oxford: Routledge.

Börjeson, L., M. Höjer, K.-H. Dreborg, T. Ekvall, and G. Finnveden. 2006. Scenario types and techniques: Towards a user's guide. Futures 38 (7): 723-739. doi:10.1016/j.futures.2005.12. 002.

Dente, B. 2014. Understanding policy decisions. Cham: Springer. doi:10.1007/978-3-319-02520-9.

Dreborg, K.-H. 1996. Essence of backcasting. Futures 28 (9): 813-828. doi:10.1016/S0016-3287 (96)00044-4.

Eakin, H., and A.L. Luers. 2006. Assessing the vulnerability of social-envoronmental systems. Annuual Review of Environment and Resources 31: 365-394. doi:10.1146/annurev.energy.30. 050504.144352.

Faldi, G., S. Macchi, O. Malcor, and M. Montemurro. 2014. Participatory backcasting for climate change adaptation: supporting community reasoning on access to water in Dar es Salaam. ACCDar Project. http://www.planning4adaptation.eu/Docs/newsInfoMaterial/07-2014/Backcasting\% 20Working\%20Paper_Faldi_Macchi_Malcor_Montemurro.pdf. Accessed 28 November 2016.

Faldi, G., and M. Rossi. 2014. Climate change effects on seawater intrusion in coastal Dar es Salaam: Developing exposure scenarios for vulnerability assessment. In: Climate Change Vulnerability in Southern African Cities, eds. S. Macchi and M. Tiepolo, 57-72. Cham: Springer. doi:10.1007/978-3-319-00672-7_4 .

Folke, C. 2006. Resilience: The emergence of a perspective for social-ecological systems analyses. Global Environmental Change 16: 253-267.

Füssel, H.-M., and R.J.T. Klein. 2006. Climate change vulnerability assessments: an evolution of conceptual thinking. Climatic Change 75 (3): 301-329. doi:10.1007/s10584-006-0329-3.

Giddens, A. 2009. The politics of climate change. Cambridge: Polity Press.

Gidley, J.M., J. Fien, J.-A. Smith, D.C. Thomsen, and T.F. Smith. 2009. Participatory futures methods: Towards adaptability and resilience in climate-vulnerable communities. Environmental Policy and Governance 19 (6): 427-440. doi:10.1002/eet.524.

Hopkins, R. 2008. The transition handbook. From oil dependency to local resilience. White river junction: Chelsea Green Publishing.

IPCC. 2000. Special report on emissions scenarios. A special report of working group III of the Intergovernmental Panel of Climate Change. Cambridge: Cambridge University Press.

IPCC. 2012. Managing the risks of extreme events and disasters to advance climate change adaptation. A special report of working groups I and II of the Intergovernmental Panel on Climate Change. Cambridge: Cambridge University Press.

IPCC. 2014. Climate change 2014: Impacts, adaptation, and vulnerability. Contribution of working group II to the fifth assessment report of the IPCC. Cambridge: Cambridge University Press.

Kates, R.W., W.R. Travis, and T.J. Wilbanks. 2012. Transformational adaptation when incremental adaptations to climate change are insufficient. PNAS-Proceedings of the National Academy of Sciences of the United Stated of America 109 (19): 7156-7161. doi:10.1073/pnas.1115521109.

Lindgren, M., and H. Bandhold. 2009. Scenario planning: The link between future and strategy, 2nd ed. Basingstoke: Palgrave Macmillan. 
Mato, R.R.A.M. 2002. Groundwater pollution in urban Dar es Salaam, Tanzania: Assessing vulnerability and protection priorities. Eindhoven: University Press, Eindhoven University of Technology.

Martens, P., and J. Rotmans. 2005. Transitions in a globalizing world. Futures 37 (10): 1133-1144. doi:10.1016/j.futures.2005.02.010.

Mjemah, I.C. 2007. Hydrogeological and hydrogeochemical investigation of a coastal aquifer in Dar es Salaam, Tanzania. Gent: Ph.D. dissertation, Ghent University.

Mtoni, Y., I.C. Mjemah, K. Msindai, M. Van Camp, and K. Walraevens. 2012. Saltwater intrusion in the Quaternary aquifers of Dar es Salaam region, Tanzania. Geologica Belgica 15 (1-2): 16-25.

O'Brien, K. 2012. Global environmental change II: From adaptation to deliberate transformation. Progress in Human Geography 36 (5): 667-676.

O'Brien, K., S. Eriksen, L.P. Nygaard, and A. Schjolden. 2007. Why different interpretations of vulnerability matter in climate change discourses. Climate Policy 7 (1): 73-88.

Olsson, P., L.H. Gunderson, S.R. Carpenter, P. Ryan, L. Lebel, C. Folke, and.S. Holling. 2006. Shooting the rapids: navigating transitions to adaptive governance of social-ecological systems. Ecology and Society 11 (1): 18.

Park, S.E., N.A. Marshall, E. Jakku, A.M. Dowd, S.M. Howden, E. Mendham, and A. Fleming. 2012. Informing adaptation responses to climate change through theories of transformation. Global Environmental Change 22: 115-126.

Pelling, M. 2011. Adaptation to climate change: From resilience to transformation. Abingdon: Routledge.

Peterson, G.D., G.S. Cumming, and S.R. Carpenter. 2003. Scenario planning: a tool for conservation in an uncertain world. Conservation Biology 17 (2): 358-366.

Quist, J. 2007. Backcasting for a sustainable future: the impact after ten years. Delft: Eburon.

Quist, J., and P. Vergragt. 2006. Past and future of backcasting: The shift to stakeholder participation and a proposal for a methodological framework. Futures 38: 1027-1045.

Robinson, J. 1990. Futures under glass: A recipe for people who hate to predict. Futures 22 (8): 820-843. doi:10.1016/0016-3287(90)90018-D.

Robinson, J. 2003. Future subjunctive: Backcasting as social learning. Futures 35: 839-856.

Roche, P. 2012. A new possibility - An exciting future shaping our present. http://www. executivecoachingwithlpr.com/2012_08_01_archive.html. Accessed 5 December 2016.

Rotmans, J., R. Kemp, and M. van Asselt. 2001. More evolution than revolution: Transition management in public policy. Foresight 3 (1): 15-31. doi:10.1108/14636680110803003.

Rugai, D., and G.R. Kassenga. 2014. Climate change impacts and institutional response capacity in Dar es Salaam, Tanzania. In: Climate Change Vulnerability in Southern African cities, eds. S. Macchi, and M. Tiepolo, 39-55. Cham: Springer. doi:10.1007/978-3-319-00672-7_3.

Sappa, G., M.T. Coviello, G. Faldi, M. Rossi, A. Trotta, and S. Vitale. 2013. Analysis of the sensitivity to seawater intrusion of Dar es Salaam's coastal aquifer with regard to climate change. ACCDar Project. http://www.planning4adaptation.eu/Docs/events/WorkShopII/WP_ Activity_2.2_def.pdf. Accessed 25 November 2016.

Swart, R.J., P. Raskin, and J. Robinson. 2004. The problem of future: sustainability science and scenario analysis. Global Environmental Change 14 (2): 137-146. doi:10.1016/j.gloenvcha. 2003.10.002.

UN-Habitat. 2009. Tanzania: Dar es Salaam City Profile. Nairobi: UNION, Publishing Services Section.

URT. 2011. Dar e Salaam City Environment Outlook 2011. Dar es Salaam: Vice-President's Office, Division of Environment, United Republic of Tanzania.

URT. 2012. Population and housing census: Population distribution by administrative areas. Dar es Salaam: Ministry of Finance, National Bureau of Statistics, United Republic of Tanzania.

Van der Brugge, R., and J. Rotmans. 2007. Towards transition management of European water resources. Water Resource Management 21 (1): 249-267. doi:10.1007/s11269-006-9052-0.

Van der Heijden, K. 2005. Scenarios: The art of strategic conversation, 2nd ed. Chichester: Wiley. 
Van der Voorn, T., C. Pahl-Wostl, and J. Quist. 2012. Combining backcasting and adaptive management for climate adaptation in coastal regions: A methodology and a South African case study. Futures 44: 346-364.

Van Notten, P.W.F., J. Rotmans, M.B.A. van Asselt, and D.S. Rothman. 2003. An updated scenario typology. Futures 35 (5): 423-443. doi:10.1016/S0016-3287(02)00090-3 .

Vergragt, P.J., and J. Quist. 2011. Backcasting for sustainability: Introduction to the special issue. Technological Forecasting and Social Change 78 (5): 747-755. doi:10.1016/j.techfore.2011. 03.010.

Open Access This chapter is licensed under the terms of the Creative Commons Attribution 4.0 International License (http://creativecommons.org/licenses/by/4.0/), which permits use, sharing, adaptation, distribution and reproduction in any medium or format, as long as you give appropriate credit to the original author(s) and the source, provide a link to the Creative Commons license and indicate if changes were made.

The images or other third party material in this chapter are included in the chapter's Creative Commons license, unless indicated otherwise in a credit line to the material. If material is not included in the chapter's Creative Commons license and your intended use is not permitted by statutory regulation or exceeds the permitted use, you will need to obtain permission directly from the copyright holder.

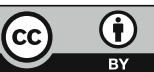

